\title{
Development of specific primers for Fusarium oxysporum causing damping off of Lilium formolongi
}

\author{
Takeshi Toda $^{1 *} \mathbb{D}$, Shun Hanesaka', Kuniaki Shishido ${ }^{2}$, Shin-ichi Fuji ${ }^{1}$ and Hiromitsu Furuya ${ }^{1}$
}

\begin{abstract}
Primers specific for the hypothetical forma specialis of Fusarium oxysporum were designed to amplify DNA from this pathogenic fungus that infects plants including lilies. The F. oxysporum sequence between the transposal elements han and hop was used for primer design. Three primer pairs designed from this region were confirmed as specific for 24 isolates of F. oxysporum pathogenic to lilies, except for one pathogenic isolates as extraordinary. No amplification was observed from F. oxysporum non-pathogenic to lily, from 12 forma specialis, and 14 fungi and oomycetes concerned with Liliaceae plants. We propose that specific primers designed from this region will be useful to detect isolates of $F$. oxysporum that are pathogenic to lilies.
\end{abstract}

Keywords: Lilium formolongi, Transposable element, Forma specialis specific

\section{Introduction}

Lilium formolongi, known as "Shin-Teppo Yuri" in Japanese, is a lily generated from a cross between $L$. longiflorum and L. formosanum, and has been grown on an open-field system in Japan. The flowers of this plant are harvested within 1 year after seeding and replanted every 2 years. Recently, stunted stem growth has been frequently observed at the second cropping season in northern Japan. Stunted lilies have yellow or brownish leaves and yellow or brown roots. Fusarium-like fungi have been isolated from the roots of lily plants. These isolates were identified as Fusarium oxysporum based on their morphology, and pathogenicity was confirmed by an inoculation of the seedlings [1].

Fusarium oxysporum, including non-pathogenic varieties, exists ubiquitously in soil. Therefore, a prompt detection technique for pathogenic F. oxysporum is desirable. The detection of pathogenic fungi using polymerase chain reaction (PCR) is a popular technique for rapid diagnosis. However, it is difficult to design specific primers for $F$. oxysporum forma specialis because their

\footnotetext{
* Correspondence: ttoda@akita-pu.ac.jp

${ }^{1}$ Department of Bioproduction Science, Faculty of Bioresource Science, Akita Prefectural University, 241-438 Kaidobata-Nishi, Shimoshinjo-Nakano, Akita 010-0195, Japan

Full list of author information is available at the end of the article
}

ribosomal DNA sequences and housekeeping genes among forma specialis are very similar [2, 3]. Najafiniya and Sharma [4] reported that random amplified polymorphic DNA markers were available for designing the specific primer for $F$. oxysporum f. sp. cucumerinum. Also, several reports suggested that the region within or next to transposable elements are useful to design forma specialis- or race-specific primers; impla in F. oxysporum f. sp. dianthi [5], and the region between han and skippy in F. oxysporum f. sp. fragariae [6]. In this study, the primer pairs were designed from the regions between transposable elements for the specific detection of $F$. oxysporum pathogenic to lilies.

\section{Materials and methods}

Isolates of $F$. oxysporum were obtained from the roots of Lilium formolongi grown at Fukushima Prefecture in Japan. Among seven isolates, pathogenicity on lily plants was confirmed for four isolates by Hanesaka et al. [1], named as lily isolates (Table 1). Tester isolates of $F$. oxysporum described below were used to confirm the specificity of designed primers. An isolate of $F$. oxysporum f. sp. lilii (CBS 130322) was provided by the Westerdijk Fungal Biodiversity Institute (Utrecht, the Netherlands). One isolate of $F$. oxysporum f. sp. cucumerinum isolate and two 
Table 1 Isolates of Fusarium oxysporum obtained from lily used in this study and amplifications by different primer pairs

\begin{tabular}{|c|c|c|c|c|c|c|c|c|c|}
\hline \multirow{2}{*}{$\begin{array}{l}\text { Isolate } \\
\text { no. }\end{array}$} & \multirow{2}{*}{$\begin{array}{l}\text { Pathogenicity } \\
\text { to lily }\end{array}$} & \multirow{2}{*}{$\begin{array}{l}\text { Host } \\
\text { plants }\end{array}$} & \multirow[t]{2}{*}{ Origin } & \multicolumn{6}{|c|}{ Designed primer pairs } \\
\hline & & & & $\mathrm{F} 1 / \mathrm{R}^{2)}$ & $\mathrm{F} 1 / \mathrm{R} 2$ & F2/R1 & F2/R2 & $\mathrm{F} 3 / \mathrm{R} 1$ & F3/R2 \\
\hline A1-4 & $+{ }^{1)}$ & Lily & Fukushima, Japan & $+{ }^{3)}$ & + & + & \pm & + & + \\
\hline$A 2-4$ & + & Lily & Fukushima, Japan & + & + & + & \pm & + & + \\
\hline$A 2-5$ & + & Lily & Fukushima, Japan & + & + & + & \pm & + & + \\
\hline D2-1 & + & Lily & Fukushima, Japan & + & + & + & \pm & + & + \\
\hline$A 2-3$ & - & Lily & Fukushima, Japan & - & - & - & - & - & - \\
\hline D1-1 & - & Lily & Fukushima, Japan & - & - & - & - & - & - \\
\hline D2-4 & - & Lily & Fukushima, Japan & - & - & - & - & - & - \\
\hline $\mathrm{Ff}-3$ & + & Lily & Fukushima, Japan & \pm & NT & \pm & NT & + & NT \\
\hline Ff-9 & + & Lily & Fukushima, Japan & + & NT & + & NT & + & NT \\
\hline $\mathrm{Ff}-10$ & + & Lily & Fukushima, Japan & + & NT & + & NT & + & NT \\
\hline Ff-13 & + & Lily & Fukushima, Japan & + & NT & + & NT & + & NT \\
\hline $\mathrm{Ff}-18$ & + & Lily & Fukushima, Japan & \pm & NT & \pm & NT & + & NT \\
\hline $\mathrm{Ff}-24$ & + & Lily & Fukushima, Japan & + & NT & + & NT & + & NT \\
\hline Ff-31 & + & Lily & Fukushima, Japan & \pm & NT & \pm & NT & + & NT \\
\hline Ff-33 & + & Lily & Fukushima, Japan & \pm & NT & \pm & NT & + & NT \\
\hline Fc-58 & + & Lily & Fukushima, Japan & + & NT & \pm & NT & + & NT \\
\hline Fc-59 & + & Lily & Fukushima, Japan & + & NT & \pm & NT & + & NT \\
\hline Fc-61 & + & Lily & Fukushima, Japan & + & NT & \pm & NT & + & NT \\
\hline Fc-62 & + & Lily & Fukushima, Japan & + & NT & \pm & NT & + & NT \\
\hline Fc-65 & + & Lily & Fukushima, Japan & + & NT & + & NT & + & NT \\
\hline Fc-66 & + & Lily & Fukushima, Japan & \pm & NT & \pm & NT & + & NT \\
\hline Fc-69 & + & Lily & Fukushima, Japan & + & NT & \pm & NT & + & NT \\
\hline Fc-70 & + & Lily & Fukushima, Japan & + & NT & \pm & NT & + & NT \\
\hline Fc-72 & + & Lily & Fukushima, Japan & + & NT & \pm & NT & + & NT \\
\hline Fc-74 & + & Lily & Fukushima, Japan & + & NT & \pm & NT & + & NT \\
\hline Fc-77 & + & Lily & Fukushima, Japan & + & NT & + & NT & + & NT \\
\hline Fc-78 & + & Lily & Fukushima, Japan & + & NT & + & NT & + & NT \\
\hline $\mathrm{Ff}-4$ & - & Lily & Fukushima, Japan & - & NT & - & NT & - & NT \\
\hline $\mathrm{Ff}-4$ & - & Lily & Fukushima, Japan & - & NT & - & NT & - & NT \\
\hline $\mathrm{Ff}-3$ & - & Lily & Fukushima, Japan & - & NT & - & NT & - & NT \\
\hline $\mathrm{Ff}-7$ & - & Lily & Fukushima, Japan & - & NT & - & NT & - & NT \\
\hline $\mathrm{Ff}-8$ & - & Lily & Fukushima, Japan & - & NT & - & NT & - & NT \\
\hline $\mathrm{Ff}-11$ & - & Lily & Fukushima, Japan & - & NT & - & NT & - & NT \\
\hline$F f-12$ & - & Lily & Fukushima, Japan & - & NT & - & NT & - & NT \\
\hline Ff-16 & + & Lily & Fukushima, Japan & - & NT & - & NT & - & NT \\
\hline
\end{tabular}

1) Pathogenicity to lilies was shown by Hanesaka et al. (2014); +: virulent to lily; -: non-virulent; NT not tested

2) Pairs of Lhs-F1, -F2, -F3, -R1, and -R2 are listed

3) + amplified products were observed, \pm faint products were observed, - no amplification was observed

isolates of $F$. oxysporum f. sp. fragariae were obtained in Japan. F. oxysporum f. sp. lycopersici race 1 , f. sp. lycopersici race 2, f. sp. melonis, f. sp. tulipae, f. sp. gladioli, f. sp. asparagi, f. sp. radicis-lycopersici, f. sp. raphani, f. sp. spinaciae, f. sp. dianthi, and $\mathrm{f}$. sp. rapae were provided by the Genebank
Project of the National Agriculture and Food Research Organization in Tsukuba, Japan (Table 2). Additionally, 14 isolates of soilborne fungi and oomycetes, reported as pathogenic to lily or possibly concerned with Liliaceae plants, were used for confirming the primers' specificity (Tables 1 and 2). 
Table 2 Isolates of Fusarium oxysporum, soilborne fungi, and oomycetes used in this study and amplifications by different primer pairs

\begin{tabular}{|c|c|c|c|c|c|c|c|c|c|}
\hline \multirow[t]{2}{*}{ Species of isolates } & \multirow[t]{2}{*}{ Host plants } & \multirow[t]{2}{*}{ Origin } & \multirow[t]{2}{*}{ Others } & \multicolumn{6}{|c|}{ Designed primer pairs } \\
\hline & & & & $\overline{\mathrm{F} 1 / \mathrm{R} 1^{2)}}$ & F1/R2 & F2/R1 & $\mathrm{F} 2 / \mathrm{R} 2$ & F3/R1 & F3/R2 \\
\hline F. oxysporum f.sp. lilii & Lily & Netherlands & CBS 1303221) & $+{ }^{3)}$ & + & + & - & + & + \\
\hline F. oxysporum f.sp. gladioli & Gladiolus & Japan & MAFF305610 & - & - & - & - & - & - \\
\hline F. oxysporum f.sp. tulipae & Tulip & Japan & MAFF235105 & - & - & - & - & - & - \\
\hline F. oxysporum f.sp. cucumerinum & Cucumber & Aomori, Japan & - & - & - & - & - & - & - \\
\hline F. oxysporum f.sp. lycopersici r.1 & Tomato & Japan & MAFF103037 & - & - & - & - & - & - \\
\hline F. oxysporum f. sp. Iycopersici r.2 & Tomato & Japan & MAFF238899 & - & - & - & - & - & - \\
\hline F. oxysporum f.sp. melonis & Melon & Japan & MAFF239211 & - & - & - & - & - & - \\
\hline F. oxysporum f.sp. melonis & Melon & Japan & MAFF305544 & - & - & - & - & - & - \\
\hline F. oxysporum f.sp. fragariae & Strawberry & Akita, Japan & No. 1 & - & - & - & - & - & - \\
\hline F. oxysporum f.sp. fragariae & Strawberry & Akita, Japan & No. 2 & - & - & - & - & - & - \\
\hline Fusarium oxysporum f. sp. radicis-lycopersici & Tomato & Japan & MAFF103044 & - & - & - & - & - & - \\
\hline Fusarium oxysporum f. sp. raphani & Radish & Japan & MAFF103057 & - & - & - & - & - & - \\
\hline Fusarium oxysporum f. sp. spinaciae & Spinach & Japan & MAFF103059 & - & - & - & - & - & - \\
\hline Fusarium oxysporum f. sp. dianthi & Carnation & Japan & MAFF103072 & - & - & - & - & - & - \\
\hline Fusarium oxysporum f. sp. rapae & Turnip leaf & Japan & MAFF240321 & - & - & - & - & - & - \\
\hline Botrytis tulipae & Tulip & Japan & MAFF245223 & - & - & - & - & - & - \\
\hline Botrytis sp. & Korean ginseng & Japan & - & - & - & - & - & - & - \\
\hline Rhizopus stolonifer & Pandanus sp. & Japan & MAFF238790 & - & - & - & - & - & - \\
\hline Cylindrocarpon destructans & Strawberry & Japan & MAFF306591 & - & - & - & - & - & - \\
\hline Penicillium sp. & Ornithogalum sp. & Japan & - & - & - & - & - & - & - \\
\hline Rhizoctonia solani AG-4 & Unknown & Japan & - & - & - & - & - & - & - \\
\hline Sclerotium rolfsii & Tomato & Japan & - & - & - & - & - & - & - \\
\hline Calonectoria ilicicola & Soybean & Japan & - & - & - & - & - & - & - \\
\hline Verticillium dahliae & Egg plant & Japan & - & - & - & - & - & - & - \\
\hline Phytophthora nicotianae & Chinese chive & Japan & MAFF238148 & - & - & - & - & - & - \\
\hline Phytophthora cactorum & Strawberry & USA & MAFF306274 & - & - & - & - & - & - \\
\hline Phytophthora sojae & Soybean & Japan & MAFF235802 & - & - & - & - & - & - \\
\hline Pythium dissotocum & Rice & Japan & - & - & - & - & - & - & - \\
\hline Pythium spinosum & Cucumber & Japan & - & - & - & - & - & - & - \\
\hline
\end{tabular}

${ }^{11} \mathrm{CBS}$ : isolate was provided from Westerdijk Fungal Biodiversity Institute (previously Centraalbureau voor Schimmelcultures, the Netherlands). MAFF isolates were provided from the Genebank of the National Agriculture and Food Research Organization (Tsukuba, Japan)

${ }^{2)}$ Pairs of Lhs-F1, -F2, -F3, -R1, and -R2 are listed

${ }^{3)}+$ amplified products were observed, \pm faint products were observed, - no amplification was observed

Isolates were incubated on potato dextrose agar medium at $25^{\circ} \mathrm{C}$ for 3 days in the dark, and then transferred onto potato dextrose broth (PDB) for another 3 days. Mycelia were harvested by filtration, washed with sterile distilled water, blotted dry, and transferred into 2 $\mathrm{ml}$ tube. Mycelia in the tubes were ground with metal bar by a bubble crasher (Taitech Co., Ltd., Japan). DNA was extracted based on the PEX method [7].

PCR was used to amplify five transposons, han, hop, impla, hornet, and skippy, using primers hanF/R, hopF/ $\mathrm{R}$, implaF/R, hornetF/R, and skippyF/R, and the region between two transposable elements using primer pairs
hanFC/RC, hopFC/RC, implaFC/RC, hornetFC/RC, and skippyFC/RC designed by Suga et al. [6]. PCR amplification was carried out using $1 \mathrm{ng}$ of DNA in a $20 \mu \mathrm{l}$ reaction mixture with $200 \mu \mathrm{M}$ each of dNTP, $1 \mu \mathrm{M}$ of the primer pairs, $1 \times$ PCR buffer, and $0.5 \mathrm{U}$ AmpliTaq Gold (Applied Biosystems, Foster City, CA). Amplification using the DNA Thermal Cycler (ParkinElmer, Waltham, MA, USA) was done for 1 cycle of $10 \mathrm{~min}$ at $95^{\circ} \mathrm{C}$, followed by 35 cycles of $95^{\circ} \mathrm{C}$ for $1 \mathrm{~min}, 55^{\circ} \mathrm{C}$ for $1 \mathrm{~min}$, and $72^{\circ} \mathrm{C}$ for $3 \mathrm{~min}$, with a final $10 \mathrm{~min}$ at $72^{\circ} \mathrm{C}$. Amplification was observed by electrophoresis on $2 \%$ agarose gels in Tris-acetate EDTA buffer. The agarose gels were 
stained with ethidium bromide $(10 \mathrm{mg} / \mathrm{ml})$ and visualized under UV transillumination. The success of PCR was confirmed by the presence or absence of fragments from the DNA of $F$. oxysporum.

Amplified products from lily isolates were selected when the size of fragments was distinguished from other isolates, and used for sequencing reactions using a BigDye Terminator kit and a 3700XL Genetic Analyzer (Applied Biosystems). The sequences amplified by these products were used to design the primers, and PCR with designed primers was used to confirm the specificity for lily isolates.

Pathogenicity test of lily seedlings was done using an additional 27 isolates obtained from lily roots (Table 1 ). The mycelia of 27 isolates grown on PDB were collected and adjusted as $2.5 \mathrm{~g}$. Mycelia were homogenized with $100 \mathrm{ml}$ of sterilized distilled water, mixed with $450 \mathrm{~g}$ of soil (Super mix A, Sakata, Japan), and placed into pots. Five lily seedlings grown for 8 weeks (Murakami seed, Ibaragi, Japan) were planted in each pot containing infested soil, and an additional five lily seedlings for control were also planted in non-infested soil. These pots were incubated at $22-27^{\circ} \mathrm{C}$ for 4 weeks. When two to five lily seedlings were dead or showed stunting with yellow leaves, isolates inoculated into that pot were considered pathogenic to lilies. When no stunting was observed or only one seedling was stunted, isolates were considered not pathogenic. These isolates were also used for PCR with designed primers.

\section{Results and discussion}

A single $550 \mathrm{bp}$ product was amplified from some lily isolates using primer pair hopRC/hanFC (TTATTC GCACGACCGGTGGTG/ GAACCCTCCAACATTCAA CA), and a product with $550 \mathrm{bp}$ was not amplified from non-pathogenic or other isolates of F. oxysporum (Fig. 1).
DNA sequence of this product from isolate A2-1 was deposited in Genebank (accession no. LC387464). This sequence was not matched with any sequences based on blastn suit search in National Center for Biotechnology Information. Several PCR products by other primers were amplified from lily isolates, but the sizes were not distinguished from other $F$. oxysporum. In addition, there were no useful sequences in five transposons between lily isolates and other tester $F$. oxysporum.

Five regions within the sequence amplified by primer pair hopRC/hanFC were used to design the primers. Three regions, Lhs-F1 (TTGAGACTTTGGGGAGGG AGATTT), -F2 (GCTTTGGACTTGAGACTTTGGGG A), and -F3 (CTGCCTTGACTATCTCTAA GCTTT), were used for forward primers, while Lhs-R1 (GTAGCC TACAGCTATCT AT) and -R2 (TCTACCAAATCTAT CTACA) were for reverse primers. The primer pairs Lhs-F1/R1, F1/R2, F2/R1, F2/R2, and F3/R1 amplified single products with approximately $350 \mathrm{bp}$ from lily isolates and F. oxysporum f. sp. lilii (CBS 130322) (Fig. 2 and Table 1), while no products were obtained from other isolates (Tables 1 and 2).

Pathogenicity test resulted that 21 isolates among 28 additional isolates were confirmed as pathogenic, and reisolation was confirmed from the roots of grown lily. Amplification by primer pairs Lhs-F1/R1, F2/R1, and F3/R1 was obtained from the 20 isolates (Table 2). From these, three primer pairs detected about $95 \%$ of F. oxysporum pathogenic to lily. Pathogenic isolate Ef16 would not be lily isolate; however, it was low frequency as less than $5 \%$. Although these primers are still imperfect for preliminary identification of pathogenic F. oxysporum, inoculation test indicated that these primer pairs can consistently amplify the fragments of pathogenic isolates. Therefore, these primer pairs are useful for quick diagnosis of this soilborne lily disease or monitoring the pathogens in commercial

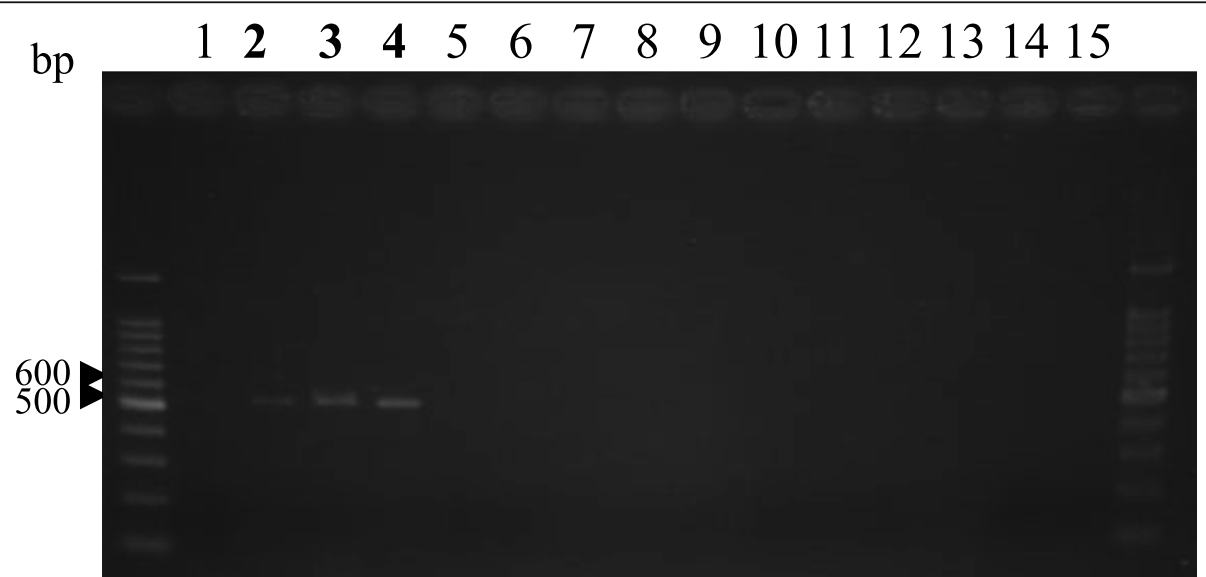

Fig. 1 Amplified products obtained by the primer pair hopRC/hanFC. Lanes 1-4: lily isolates of Fusarium oxysporum pathogenic to lilies; lanes 5-7: non-pathogenic isolates of $F$. oxysporum obtained from lily roots; lane 8-14: tester isolates of F. oxysporum; lane 15: negative control. Marker used was 100 ladder marker 


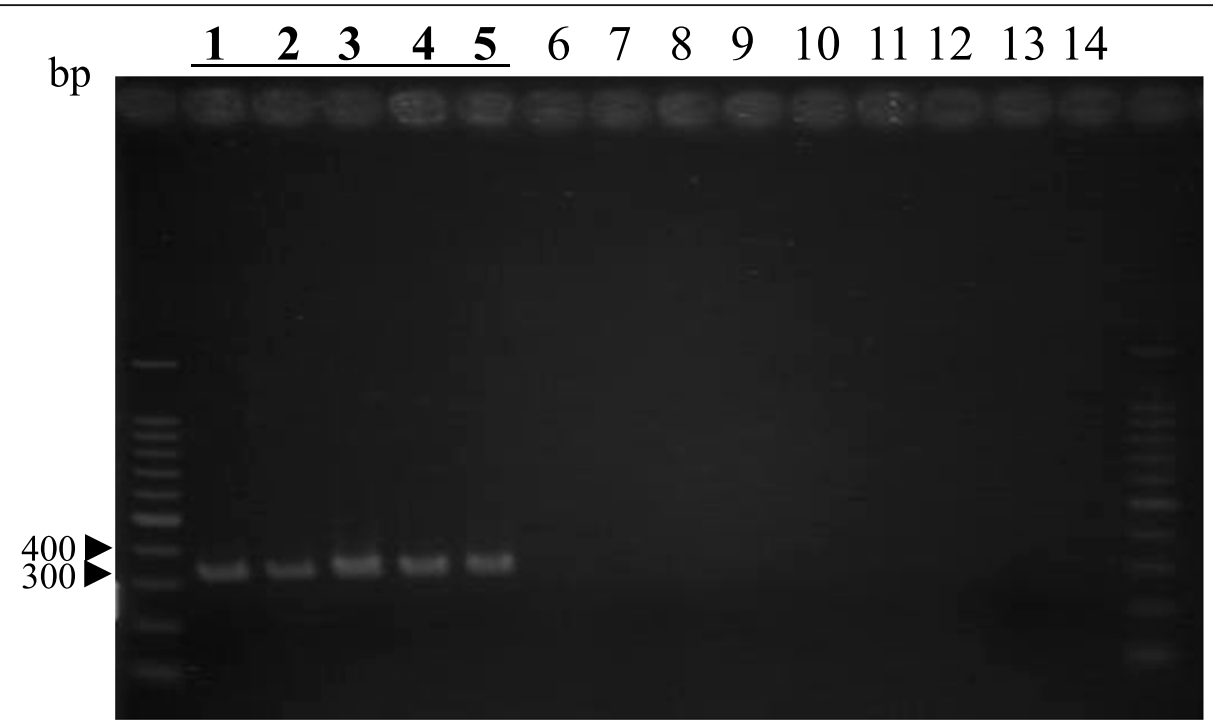

Fig. 2 Amplified products obtained by the primer pair Lhs-F1/R1. Lanes 1-4: lily isolates of Fusarium oxysporum pathogenic to lilies; lane 5: F. oxysporum f. sp. lilii; lanes 6-13: tester isolates of F. oxysporum; lane 14: negative control. Marker used was 100 ladder marker

fields, as it is difficult and time-consuming to identify or specify the pathogens in the soil.

Pathogenicity to lilies has been observed from $F$. oxysporum f. sp. lilii, f. sp. gladioli, and f. sp. tulipae [8]. We herein observed amplification by three primer pairs from tester F. oxysporum f. sp. lilii, but not from f. sp. gladioli or f. sp. tulipae. Baayen et al. [8] reported that tester isolate CBS130322 of $F$. oxysporum f. sp. lilii was not pathogenic in their experiment and that this isolate was different Vegetative Compatibility Group (VCG) from other $F$. oxysporum f. sp. lilii. It is possible that this isolate would reduce the pathogenicity to lily by long-time incubation, and that several different VCGs were categorized into the same forma specialis within $F$. oxysporum [8]. We therefore suggest that $F$. oxysporum lily isolates obtained from lilies grown in Japan would be close to $F$. oxysporum f. sp. lilii.

In summary, because transposable elements exist randomly in the genome of $F$. oxysporum, we considered that several of these or related regions would be unique to forma speciales. Therefore, we designed primers specific for the hypothetical forma specialis of $F$. oxysporum that is pathogenic to lilies following the methodology of [6]. Specific primers were identified in the sequence between the two transposable elements han and hop, and the specificity of three primer pairs was confirmed using F. oxysporum lily isolates causing stunting of lily seedlings (Table 2). These primer combinations will be useful for the direct detection of amplified fragments obtained from pathogenic F. oxysporum in lily roots, although future studies should confirm the possibility of quick detection. Additionally, these primers will help to clarify whether isolates of $F$. oxysporum obtained from lily roots or the soil are pathogenic to lilies.

\section{Abbreviations}

F. oxysporum: Fusarium oxysporum; f. sp.: Forma specialis; PCR: Polymerase chain reaction; DNA: Deoxyribonucleic acid; CBS: Westerdijk Fungal Biodiversity Institute (previously Centraalbureau voor Schimmelcultures, the Netherlands); MAFF: Isolates provided from the Genebank of the National Agriculture and Food Research Organization (Tsukuba, Japan); PDB: Potato dextrose broth; VCG: Vegetative compatibility group

\section{Acknowledgements}

We thank Sarah Williams, PhD, from Edanz Group (www.edanzediting.com) for editing a draft of this manuscript.

\section{Authors' contributions}

$\Pi \mathrm{T}$ and $\mathrm{SH}$ designed the primers and analyzed the specificity of primers for lily isolates. KS examined the pathogenicity test. All authors read approved the manuscript.

\section{Funding}

This manuscript was not supported by the funding.

Availability of data and materials

All data generated or analyzed during this study are included in this published article.

Ethics approval and consent to participate Not applicable.

\section{Consent for publication}

Not applicable.

\section{Competing interests}

The authors declare that they have no competing interests.

\section{Author details}

'Department of Bioproduction Science, Faculty of Bioresource Science, Akita Prefectural University, 241-438 Kaidobata-Nishi, Shimoshinjo-Nakano, Akita 010-0195, Japan. ${ }^{2}$ Fukushima Prefecture Office, 2-16 Sugitsuma-cho, Fukushima 960-8670, Japan. 
Received: 9 August 2019 Accepted: 21 November 2019

Published online: 06 January 2020

References

1. Hanesaka S, Shishido K, Toda T, Fuji S, Furuya H (2014) Clarifying factor of replant failure on Lilium $x$ formolongi in Fukushima prefecture and useful assay of fungal community in roots. Jpn J Phytopatol 80:266 (In Japanese Abstract)

2. Geiser DM, del Mar Jimenez-Gasco M, Kang S, Makalowska I, Veeraraghavan N, Ward TJ, Zhang N, Kuldau GA, O'Donnell K (2004) FUSARIUM-ID v. 1.0: A DNA sequence database for identifying Fusarium. Eur J Plant Pathol 110: 473-479

3. Hirano Y, Arie T (2009) Variation and Phylogeny of Fusarium oxysporum Isolates Based on Nucleotide Sequences of Polygalacturonase Genes. Microbes Environ 24:113-120

4. Najafiniya M, Sharma P (2011) Specific PCR-based marker for detection of pathogenic groups of Fusarium oxysporum f.sp. cucumerinum in India. J Genet Eng Biotechnol 9:29-24

5. Chiocchetti A, Bernardo I, Daboussi MJ, Garibaldi A, Gullino ML, Langin T, Migheli Q (1999) Detection of Fusarium oxysporum f. sp. dianthi in carnation tissue by PCR amplification of transposon insertions. Phytopathology 89: 1169-1175

6. Suga H, Hirayama Y, Morishita M, Suzuki T, Kageyama K, Hyakumachi M (2013) Development of PCR primers to identify Fusarium oxysporum f. sp. fragariae. Plant Dis 97:619-625

7. Nakahara K, Hataya T, Uyeda I (1999) A simple, rapid method of nucleic acid extraction without tissue homogenization for detecting viroids by hybridization and RT-PCR. J Virol Methods 77:47-58

8. Baayen RP, Forch MG, Waalwijk C, Bonants PJM, Loffler HJM, Roebroeck EJA (1998) Pathogenic, genetic and molecular characterisation of Fusarium oxysporum f.sp. lilii. Eur J Plant Pathol 104:887-894

\section{Publisher's Note}

Springer Nature remains neutral with regard to jurisdictional claims in published maps and institutional affiliations.

\section{Submit your manuscript to a SpringerOpen ${ }^{\circ}$ journal and benefit from:}

- Convenient online submission

- Rigorous peer review

- Open access: articles freely available online

- High visibility within the field

- Retaining the copyright to your article

Submit your next manuscript at $\boldsymbol{\nabla}$ springeropen.com 